\title{
Regeneración de tejido blando en una clase 3 mediante un colgajo desplazado lateral e injerto de tejido conjuntivo. Reporte de un caso clínico.
}

\section{Elian class 3 regeneration of soft tissue using a laterally moved flap and connective tissue graft. A clinical case report}

\author{
Javier Basualdo ${ }^{1,2^{*}}$, Soledad Acuña ${ }^{3}$, Enrique Javer ${ }^{2,4}$, Carlos Godoy², 4 \\ Rodrigo Jorquera ${ }^{2,4}$, Elizabeth Lozano ${ }^{2}$
}

\begin{abstract}
1. Profesor Asistente, Programa de Especialización en Implantología Buco Máxilo Facial. Facultad de Odontología, Universidad de Chile, Chile. 2. Docente Diplomado de Cirugía Plástica Periodontal e Implantológica, Facultad de Odontología, Universidad de Chile, Chile. 3. Estudiante del Postítulo de Implantología Buco Máxilo Facial. Universidad de Chile, Chile.

4. Profesor Adjunto, Programa de Periodoncia, Facultad de Odontología, Universidad de Chile, Chile.
\end{abstract}

*Correspondencia a: Javier Basualdo Allende | Dirección: Av. Santa María 0596. Providencia,

Santiago, Chile. | Telefono: +569 89046734 |

E-mail: drjavierbasualdo@gmail.com

Trabajo recibido el 01/05 /2019.

Aprobado para su publicación el 17/09/2019

\begin{abstract}
RESUMEN
Se describe el caso clínico de una paciente de 60 años, sexo femenino, sana, la cual presentaba en el diente 1.1 una recesión de $6 \mathrm{~mm}$ de longitud con extensa pérdida ósea en vestibular correspondiente a una clase 3 de Elian. En el presente reporte se expone los pasos que se siguieron para llegar a una Clase 2 de Elian, mediante un colgajo desplazado lateral con injerto de tejido conjuntivo subepitelial.
\end{abstract}

PALABRAS CLAVE

Injerto de tejido conectivo; Colgajo desplazado lateral; Cirugía plástica periodontal.

Rev. Clin. Periodoncia Implantol. Rehabil. Oral Vol. 00(0); 00-00, 2019.

\section{ABSTRACT}

We describe the clinical case of a 60 -year-old female patient, healthy, who presented a $6 \mathrm{~mm}$-long recession on tooth 1.1 with extensive vestibular bone loss corresponding to an Elian class 3 . In the present report, the steps followed to reach an Elian class 2, by means of a laterally moved flap with subepithelial connective tissue graft, are shown.

KEYWORDS

Connective tissue graft; Laterally moved flap; Periodontal plastic surgery

Rev. Clin. Periodoncia Implantol. Rehabil. Oral Vol. 12(3); 140-143, 2019.

\section{INTRODUCCIÓN}

En la actualidad la instalación de un implante dental inmediato en un alveolo clase 3 no está indicado debido a la falta de tejido duro y blando(1). No obstante, en una clase 2 , sí es posible instalar un implante simultáneo con la regeneración de la tabla ósea vestibular, siempre y cuando exista suficiente remante óseo ${ }^{(2)}$.

Diversas técnicas de cirugía plástica periodontal han sido desarrolladas y propuestas (colgajos pediculados e injertos libres) para corregir defectos en recesiones gingivales con diferentes grados de éxito ${ }^{(3)}$. La selección de una u otra técnica va a depender de las características anatómicas del sitio a tratar y de las demandas propias del paciente. El paciente influye en la selección de la técnica quirúrgica, especialmente cuando afecta la zona estética, debido a la exposición de la superficie radicular durante la sonrisa y/o función ${ }^{(4)}$.

La técnica de colgajo desplazado lateral corresponde al grupo de los colgajos pediculados rotados ${ }^{(3)}$. El colgajo desplazado lateral fue originalmente descrito por Grupe y Warren en el año 1956, cuya principal falencia era la poca predictibilidad en la generación de un defecto/recesión gingival del diente donante, y consistía básicamente en el avance coronal del colgajo desplazado lateralmente a espesor total(5). Con el fin de reducir el riesgo de recesión gingival en el sitio donante, Staffileno ${ }^{(6)}$ propuso el uso de un colgajo de espesor parcial, en lugar de una de espesor total, para cubrir la exposición radicular.

De acuerdo a Zucchelli el colgajo desplazado lateral está indicado cuando están presentes algunas condiciones anatómicas locales desfavorables que pueden hacer que el colgajo desplazado coronal esté contraindicado, estas son: 1) Ausencia de tejido queratinizado apical al defecto de la recesión, 2) Presencia de la fisura de Stillman que se extiende hacia la mucosa alveolar, 3) Inserción marginal del frenillo, 4) Presencia de una profunda pérdida de estructura radicular, 5) Vestíbulo poco profundo. En estos casos la técnica de colgajo desplazado lateral está indicada en el tratamiento de recesiones gingivales de dientes aislados, cuyos dientes vecinos no presenten recesiones gingivales y frenillos que dificulten la técnica(4).

En la actualidad la técnica de colgajo desplazado lateral de Zucchelli(4) es una de las más utilizadas, aunque también puede ser modificado mediante el uso de un injerto de tejido conectivo para cambiar el fenotipo gingival de la zona a intervenir. Figura 1

El objetivo de la presentación de este caso clínico es mostrar la resolución de una recesión unitaria extensa, mediante el uso de un colgajo desplazado lateral e injerto de tejido conjuntivo subepitelial. Además de cambiar de una clase 3 a una clase 2, con el fin de lograr las condiciones ideales para poder realizar una regeneración ósea guiada y la instalación de un Implante Dental.

\section{INFORME DEL CASO}

Se presenta el caso clínico de una paciente sana género femenino de 60 años. Sin antecedentes de alergias ni consumo de tabaco. Al examen clínico se evidencia una extensa recesión RT1 de Cairo(11) clase B - ${ }^{(12)}$ en relación al diente 1.1 de $6 \mathrm{~mm}$, el cual presentaba una restauración cervical con composite y movilidad tipo 1. Figura 2. Al examen imagenológico se evidencia una pérdida total de la tabla vestibular y una parte del hueso en relación al ápice de diente. Figura 3. La indicación inicial fue la regeneración ósea y la planificación de un implante. No obstante, la falta de tejido blando y duro en vestibular, hicieron que fuera estéticamente imposible, ya que correspondía a una clase 3 de Elian por lo que no fue posible realizar una técnica de "Ice cream cone"(1) y/o la instalación del implante simultáneamente ${ }^{(2)}$. Por 


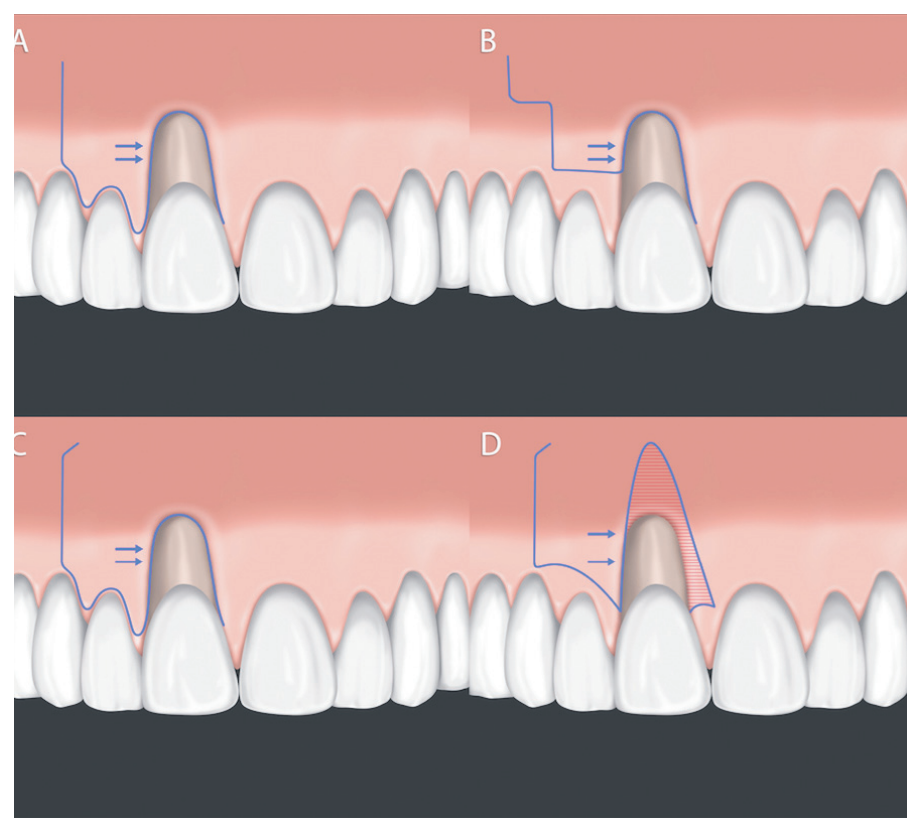

Figura 1. A) Incisión original de acuerdo a Grupe y Warren (1956); B) Diseño de Incisión modificada para proteger el margen gingival, descrita por Grupe (1966); C) Diseño de incisión con una incisión liberadora (cutback), descrita por Corn (1964); D) Diseño de incisión para proteger el margen gingival, descrita por Zucchelli y cols. (2004).

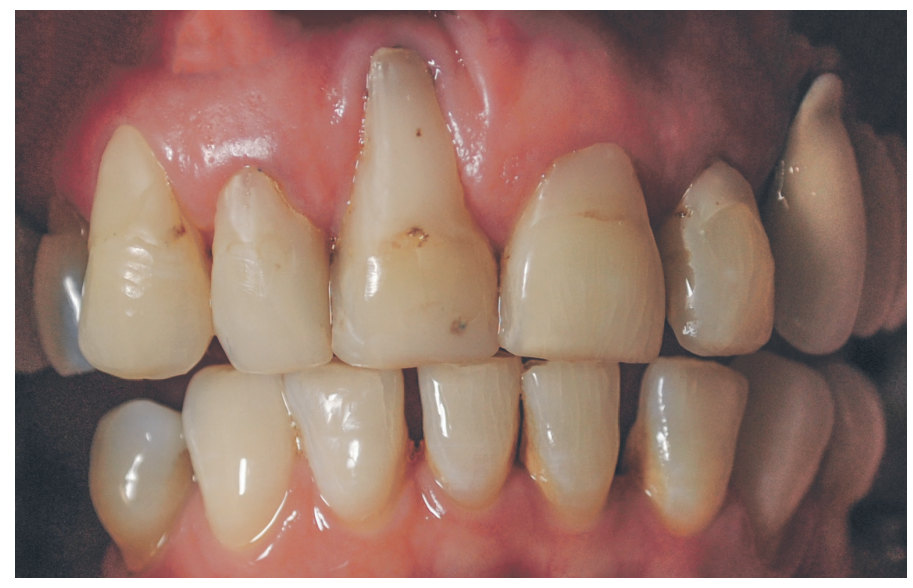

Figura 2. Situación inicial en donde se observa una recesión de $6 \mathrm{~mm}$ de largo, Clase 1 de Miller en relación al diente 1.1.

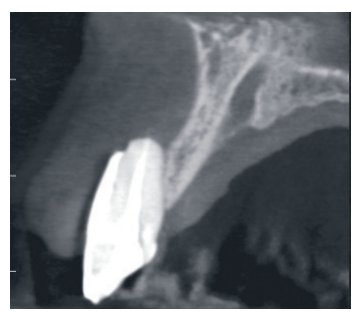

Figura 3. La imagen del cone beam muestra una compleja situación de soporte del diente 1.1, el cual requiere un implante. No obstante, corresponde a una clase 3 de Elian, por lo cual requiere una ganancia de tejido blando con el fin de convertirse en una clase 2 , para poder realizar una regeneración ósea.

lo que fue necesario regenerar primero el tejido blando y transformar de una clase 3 a una clase 2. Figura 4.

En este caso se planificó resolver la recesión del diente 1.1 mediante una técnica de colgajo desplazado lateral e injerto de tejido conjuntivo subepitelial. Figura 5.

La paciente fue premedicada con: amoxicilina $875 \mathrm{mg} \quad(1$ comprimido cada 12 horas por 7 días, iniciando el tratamiento el día de la cirugía), ketoprofeno $100 \mathrm{mg}$ ( 1 comprimido cada 12 horas por

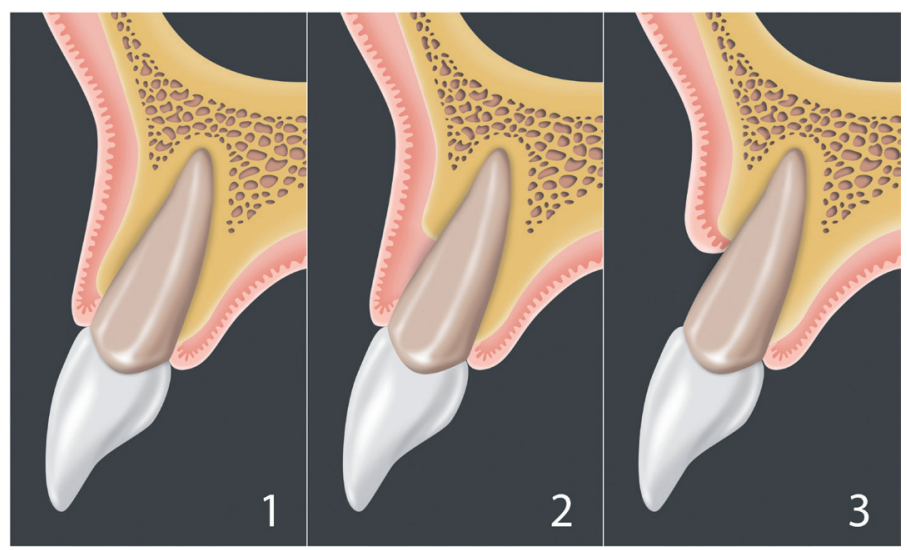

Figura 4. Clasificación de alveolo fresco post exodoncia de 3 tipos: 1) El tejido blando vestibular y la tabla ósea vestibular están a un nivel normal en relación al límite amelocementario del diente pre extraído y permanecen intactos post extracción, 2) El tejido blando vestibular está presente pero la tabla ósea vestibular se ha perdido parcialmente luego de la extracción del diente, 3) El tejido blando vestibular y la tabla ósea vestibular se han perdido luego de la extracción dentaria.

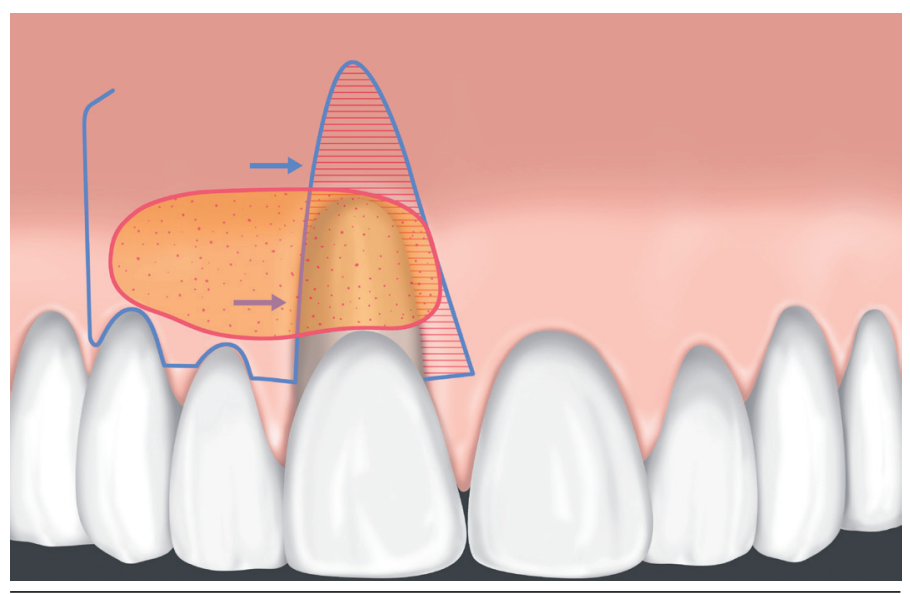

Figura 5. Planificación y diseño de la cirugía propuesta. Se realizó un colgajo desplazado lateral a espesor parcial con injerto de tejido conectivo subepitelial.

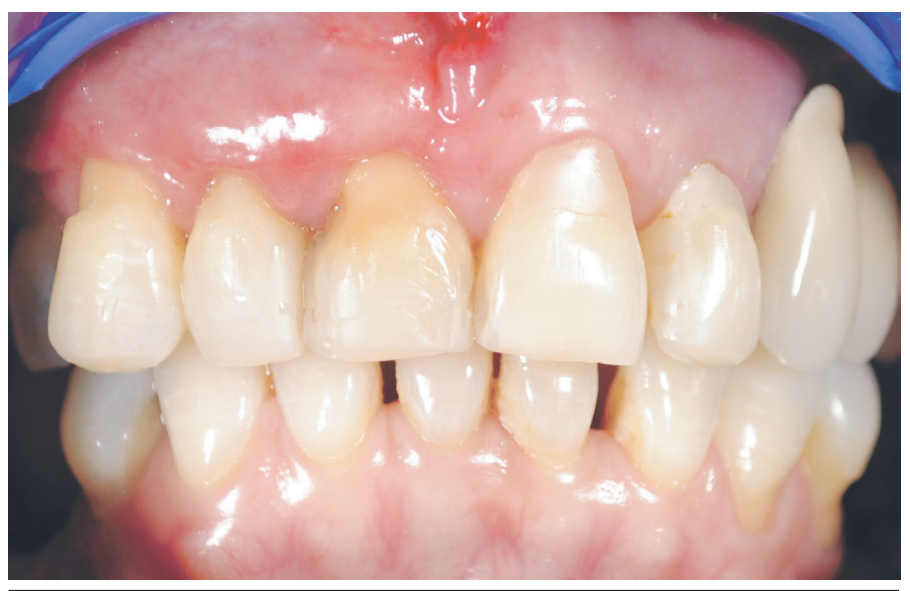

Figura 6. Control postquirúrgico a los 35 días.

3 días inmediatamente después de la cirugía), paracetamol $1 \mathrm{gr}$ (1 comprimido cada 12 horas por 3 días inmediatamente después de la cirugía) y enjuagues de clorhexidina al $0,12 \%$ (cada 12 horas por 15 días, empezando el día de la cirugía).

Se inicia la cirugía con técnica infiltrativa. Previamente se había citado a la paciente para el retiro de los composites e higiene y profilaxis, en el pabellón solo se procedió a un curetaje y alisado radicular. 


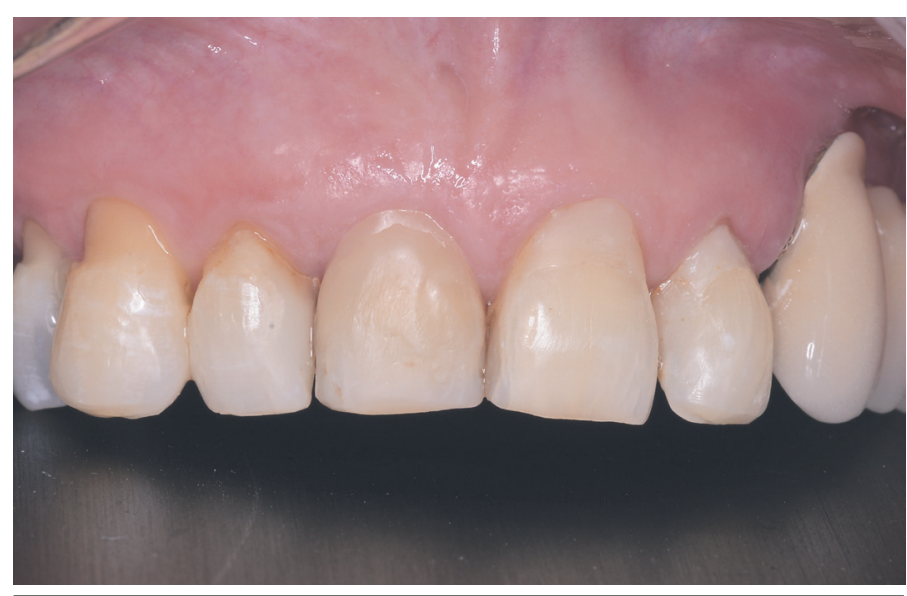

Figura 7. Control postquirúrgico a los 12 meses. En donde se aprecia un contorno gingival adecuado, una cobertura radicular completa y el paso de una Clase 3 a una clase 2 de Elian.

\section{Área Receptora}

Se realizó la profundización de espesor parcial del área receptora del colgajo de forma triangular delimitada por tres incisiones: 1) Una incisión horizontal de $2 \mathrm{~mm}$ extendida en dirección distal mesial a nive de la unión cemento-esmalte, teniendo como límite natural el frenillo labial, 2) Una incisión vertical biselada, paralela al borde gingival mesia de la recesión y sin incorporar el frenillo labial, extendiéndose hasta la mucosa alveolar, 3) Una incisión biselada intrasurcular a lo largo del borde de la encía distal del defecto de recesión y extendiéndose en la mucosa alveolar hasta cruzar la incisión vertical precedente.

La desepitelización de esta zona se realizó con una hoja de 15c mantenida paralela a la superficie gingival externa (espesor parcia superficial). Una zona de tejido conjuntivo de $2 \mathrm{~mm}$ de ancho lateral y apical a la exposición de la raíz proporcionó de lecho al injerto de tejido conectivo subepitelial y al colgajo desplazado lateralmente. El área receptora fue a espesor parcial.

\section{Área Donante}

El diseño del colgajo es a espesor parcial y consta de tres incisiones: 1) Incisión biselada, que es la misma incisión número 3 del área receptora, 2) Una incisión intrasurcular horizontal que se extiende desde distal de 1.3 hasta mesial de 1.1, respetando la base de las papilas, pero incluyendo el margen gingivodentario en el diseño del colgajo, 3) Una incisión vertical oblicua biselada, que se extiende dentro de la mucosa alveolar, paralela a la primera incisión.

Se realizó otra incisión horizontal corta en la extensión más apical de esta incisión vertical para facilitar la movilización mesial del colgajo.

\section{Toma de Injerto conectivo subepitelial del Paladar}

El tamaño del injerto fue determinado mediante una plantilla realizada con base en el sitio receptor, de acuerdo con las dimensiones del área receptora creada para recibir el injerto de tejido conectivo subepitelial y del área donante. Para la toma del injerto palatino se utilizó un bisturí $n^{\circ} 15$, realizando una incisión en dirección anteroposterior hasta llegar al periostio, alejada $2-3 \mathrm{~mm}$ del margen gingival desde el primer molar hasta los premolares del lado izquierdo, luego se realizaron 2 incisiones paralelas para la toma de injerto de conectivo subepitelial, determinando un grosor homogéneo en la toma del injerto.

El sitio dador fue suturado con seda 3-0 con suturas tipo colchonero horizontal cruzado con ancla dentaria por vestibular de molares y premolares; la zona dadora fue protegida con cemento quirúrgico. La paciente fue instruida con dieta blanda para evitar lesionar la zona dadora del paladar. Las suturas fueron retiradas a los 7 días.

\section{Sutura del injerto conectivo subepitelial al sitio receptor}

El material de sutura utilizado fue Poliglactin 910 reabsorbible $5-0$, el injerto fue fijado en la base de las papilas con suturas desde palatino a vestibular, anudando en palatino.

\section{Movilización del colgajo desplazado lateral}

El levantamiento del colgajo se realizó a espesor parcial superficial sobrepasando el límite mucogingival. El colgajo se desplazó lateralmente y coronalmente hacia el defecto quedando sobrepuesto de manera pasiva sobre él, cubriendo el injerto de tejido conectivo subepitelial, y solo dejando expuesto el extremo distal de la 1.3.

\section{Sutura del colgajo desplazado lateral}

Es recomendable comenzar la sutura fijando al periostio en el extremo más apical de las incisiones verticales y luego continuar hacia coronal, logrando una mayor pasividad del colgajo. Se colocó suturas simples a lo largo de las incisiones verticales, además se colocó frente a cada diente un colchonero horizontal cruzado anudado en palatino, de modo de afrontar el colgajo superficial al injerto conectivo y al diente de modo de evitar espacios muertos. En la zona donante se esperó la cicatrización por segunda intención. El retiro de la sutura se realizó a los 21 días.

\section{DISCUSIÓN}

Crear las condiciones favorables para la instalación de un implante aseguran el éxito del tratamiento, no solo proporcionando una cantidad suficiente de tejido duro, sino que también de tejido blando estético y funcional para poder instalar un implante. La clase 3 de Elian(1) es cuando el tejido blando vestibular y la tabla ósea vestibular se han perdido luego de la extracción dentaria, esto impide la instalación de un implante y/o la regeneración ósea inmediata a la extracción, o la hace muy dificultosa, principalmente desde el punto de vista estético. El poder lograr pasar de una clase 3 a una clase 2, que es cuando el tejido blando vestibular está presente pero la tabla ósea vestibular se ha perdido parcialmente luego de la extracción del diente ${ }^{(1)}$. De este modo en este caso particular de una recesión gingival extensa y aislada, y de acuerdo a las consideraciones de diagnóstico y tratamiento basadas en la clasificación de biotipos periodontales, recesión gingival y condiciones de superficie radicular, corresponde a un caso $D^{(12)}$, el cual requiere de cirugía, por lo que fue necesario encontrar una técnica que pudiera cubrir el tamaño de la recesión.

La técnica de colgajo desplazado lateral fue la seleccionada, principalmente por la longitud de la recesión, la cual difícilmente podría haber sido cubierta con otras técnicas como: colgajo desplazado coronal, de sobre y/o de tunel, ya que se necesitaría mucho desplazamiento y la estética del sector no lo permitiría. El colgajo desplazado lateral a espesor parcial fue acompañado de un leve desplazamiento a coronal, la descarga mesial en la línea media fue ocultada en la línea media antes del frenillo y la descarga distal fue ocultada por distal del canino, haciéndola muy estética para este caso. Otra diferencia fue la manera en como se realizó la incisión horizontal, la cual, fue crevicular y corto en la base de las papilas correspondiendo a una leve diferencia a lo descrito por Zucchelli(4). Diferentes modificaciones han sido desarrolladas al colgajo desplazado lateral, tal como se puede apreciar en la figura 1, además en este trabajo se utilizó un injerto de tejido conjuntivo para modificar el fenotipo de la zona, aportando un importante cambio en grosor de toda la zona intervenida.

Zucchelli y cols. ${ }^{(4)}$ en el 2004 publicaron un estudio en que se describe el tratamiento de ciento veinte recesiones gingivales aisladas (Clase Miller I o II) con características específicas del tejido queratinizado lateral a los defectos con un nuevo abordaje de la técnica de colgajo desplazado lateral. Los participantes del estudio cumplieron con: 1) Defecto aislado (sin recesiones en los dientes vecinos), 2) Defecto clase I o II de Miller ( blandos y duros), 3) Profundidad de recesión $>2 \mathrm{~mm}, 4$ ) Ancho de tejido queratinizado del lado donante de al menos $6 \mathrm{~mm}$ mayor que el ancho de la recesión, medido a nivel de la unión cemento-esmalte y 5) Altura del tejido queratinizado del lado donante al menos $2 \mathrm{~mm}$ mayor que la profundidad de sondaje del diente donante.

Las principales modificaciones quirúrgicas consistieron en el avance coronal del colgajo pediculado, desplazándolo lateralmente y en diferentes espesores parciales durante la elevación del colgajo. La evaluación clínica de los resultados se realizó 1 año después de la cirugía. En el $97 \%$ la superficie radicular se cubrió con tejido blando y 96 defectos $(80 \%)$ mostraron cobertura radicular completa. Se observó un aumento estadístico y clínicamente significativo del tejido queratinizado. Estos resultados favorables se lograron sin cambios en la posición del margen gingival o en la altura del tejido gingival en el diente y sitio del donante. El año 2009, Chambrone ${ }^{(9)}$ realizó un estudio en 32 pacientes sistémicamente sanos con resultados favorables a 24 meses de la intervención utilizando esta técnica. La cobertura radicular media fue de un $93,8 \%$, y de ella el $62,5 \%$ obtuvo cobertura radicular completa. En 2010, Santana ${ }^{(10)}$ comparó la eficacia de las técnicas de colgajo desplazado lateral con la técnica de desplazado coronal en el tratamiento de defectos localizados en maxilar, cuyo resultado muestra que no hay diferencias significativas entre ambas técnicas.

El poder recuperar el tejido blando nos permite ahora, controlar el diente en el tiempo, aunque el pronóstico no es bueno, producto 
de la escasa cantidad de hueso remanente. No obstante, es posible realizar también la exodoncia, con preservación alveolar con una técnica regenerativa mínimamente invasiva como lo es la técnica de "ice cream cone"(1), con fin de instalar un implante dental en óptima posición, lo que era imposible en la situación inicial de este caso.

\section{CONCLUSIÓN}

De acuerdo a lo presentado en este caso clínico mediante un colgajo desplazado lateral e injerto de tejido conectivo subepitelial fue posible lograr una cobertura total de una recesión gingival de gran longitud RT1 de Cairo(11) en un diente 1.1.

\section{DECLARACIÓN DE CONFLICTO DE INTERÉS Y FUENTE DE FINANCIAMIENTO:}

Los autores declaran que no tienen ningún conflicto de interés, ni fuente de financiamiento.

\section{RESPONSABILIDADES ÉTICAS:}

Protección de personas y animales. Los autores declaran que para esta investigación no se han realizado experimentos en seres humanos ni en animales.

Confidencialidad de los datos. Los autores declaran que han seguido los protocolos de su centro de trabajo sobre la publicación de datos de pacientes.

Derecho a la privacidad y consentimiento informado. Los autores han obtenido el consentimiento informado de los pacientes y/o sujetos referidos en el articulo. Este documento obra en poder del autor de correspondencia.

\section{Bibliografía}

1. Elian N, Cho S-C, Froum S, Smith R, Tarnow D. A simplified socket classification and repair technique. Pract Proced Aesthet Dent. 2007;19:99-104.

2. Basualdo J, Ivankovic M, Kuzmicic J, Fernández E. Atraumatic extraction and immediate implant placement into infected site with the "ice cream cone" technique and L-PRF: A Case Report. Rev. Clin. Periodoncia Implantol. Rehabil. Oral. 2018;11:43-46.

3. Bouchard P, Malet J. Decision-making in aesthetics: root coverage revisted Periodontol 2000. 2001;27:97-120.

4. Zucchelli G, Cesari C, Amore C, Montebugnoli L, De Sanctis M. Laterally moved, coronally advanced flap: a modified surgical approach for isolated recession-type defects. J Periodontol. 2004;75:1734-174.

5. Grupe HE, Warren RF. Repair of gingival defects by a sliding flap operation. J Periodontol. 1956;27:92-95.

6. Staffileno $\mathrm{H}$. Management of gingival recession and root exposure problems with periodontal disease. Dent Clin North Am. 1964;3:111-120.
7. Corn $\mathrm{H}$. Edentulous area pedicle grafts in mucogingival surgery. Periodontics. 1964;2:229-242.

8. Grupe HE. Modified technique for sliding flap operation. J Periodontol. 1966;37:491-495.

9. Chambrone L. Treatment of miller class I and II localized recession defects using laterally positioned flaps: a 24-month study. Am J Dent. 2009;22:339-344.

10. Santana RB, Furtado MB, Mattos CM, de Mello Fonseca E, Dibart S. Clinical evaluation of single-stage advanced versus rotated flaps in the treatment of gingival recessions. J Periodontol. 2010;81:485-92

11. Cairo F, Nieri M, Cincinelli S, Mervelt J, Pagliaro U. The interproximal clinical attachment level to classify gingival recessions and predict root coverage outcomes: an explorative and reliability study. J Clin Periodontol. 2011;38:661-666.

12. Cortellini P, Bissada NF. Mucogingival conditions in the natural dentition: Narrative review, case definitions, and diagnostic considerations. J Clin Periodontol. 2018;45(Suppl 20):S190-S198. 